\title{
Delayed peritonitis after endoscopic ultrasound-guided fine-needle aspiration of a metastatic celiac lymph node
}

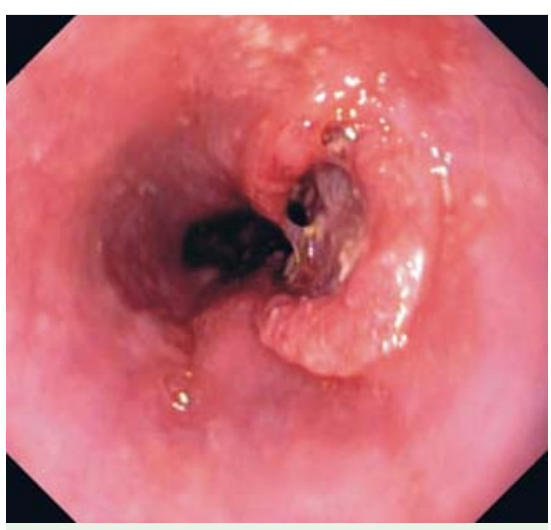

Fig. 1 Upper gastrointestinal endoscopy showed an ulcerated, exophytic tumor in the lower esophagus.

A 48-year-old man presented with dysphagia, lower retrosternal pain following food ingestion, and significant weight loss. Clinical examination found epigastric pain during palpation, while laboratory workup revealed only an elevated erythrocyte sedimentation rate.

Upper endoscopy visualized an intraluminal mass in the lower esophagus ( $\bullet$ Fig. 1), which was shown by biopsy to be a poorly differentiated squamous cell carcinoma ( $\bullet$ Fig. 2). Computed tomography (CT) scan and endoscopic ultrasound (EUS) were performed and indicated a T3N1 esophageal malignancy. EUS also visualized conglomerated lymph nodes in the vicinity of the celiac trunk and adjacent to the left liver lobe. EUSguided fine-needle aspiration (EUS-FNA) was performed with a $25-\mathrm{G}$ needle without immediate complications ( $\bullet$ Fig. 3 ). Cytology smears showed clumps of squamous cells with nuclear atypia, in a background of leukocytes ( $\bullet$ Fig. 4).

Four days later, the patient developed fever, severe diffuse abdominal pain with tenderness, and high white blood cell count. The patient was referred for surgery where laparoscopic intervention revealed necrosis of the celiac lymph nodes with generalized peritonitis. Excision of the abdominal lymph nodes was performed with peritoneal lavage and multiple drainage, with an improvement in the patient's general and local status.

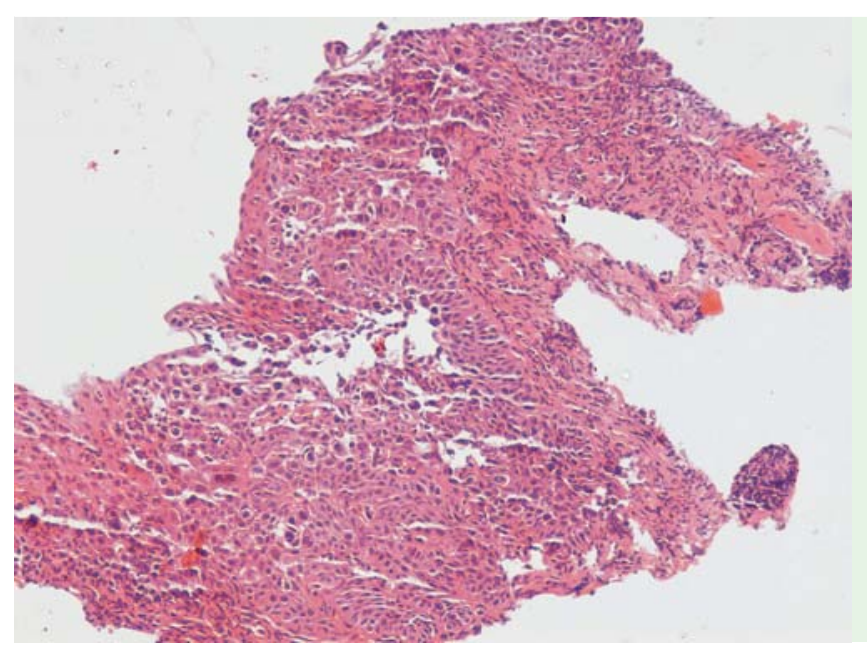

Fig. 2 Poorly differentiated squamous cell carcinoma (hematoxylin and eosin $\times 100)$.

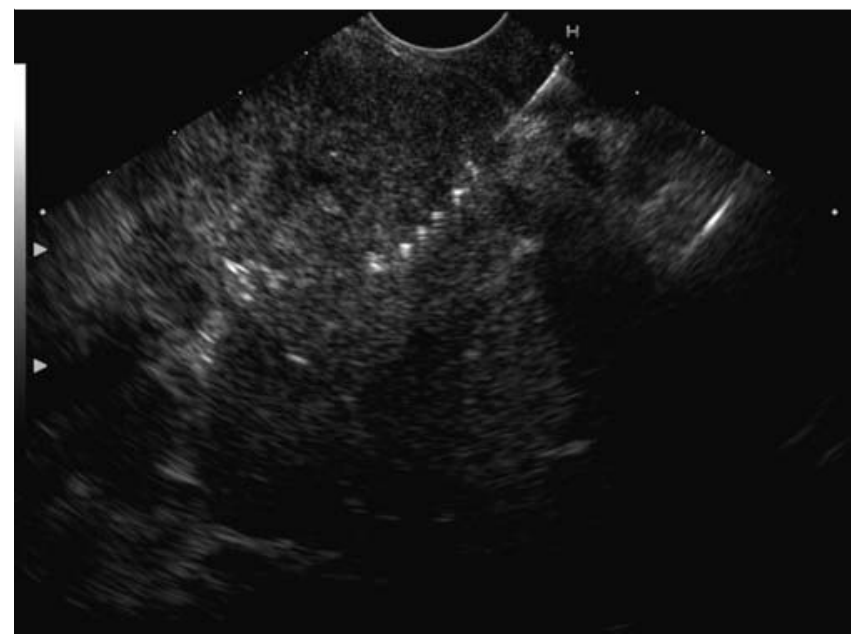

Fig. 3 Endoscopic ultrasound-guided fine-needle aspiration of the hypoechoic, inhomogeneous mass of $5 \mathrm{~cm}$ diameter localized in the vicinity of the pancreatic head.

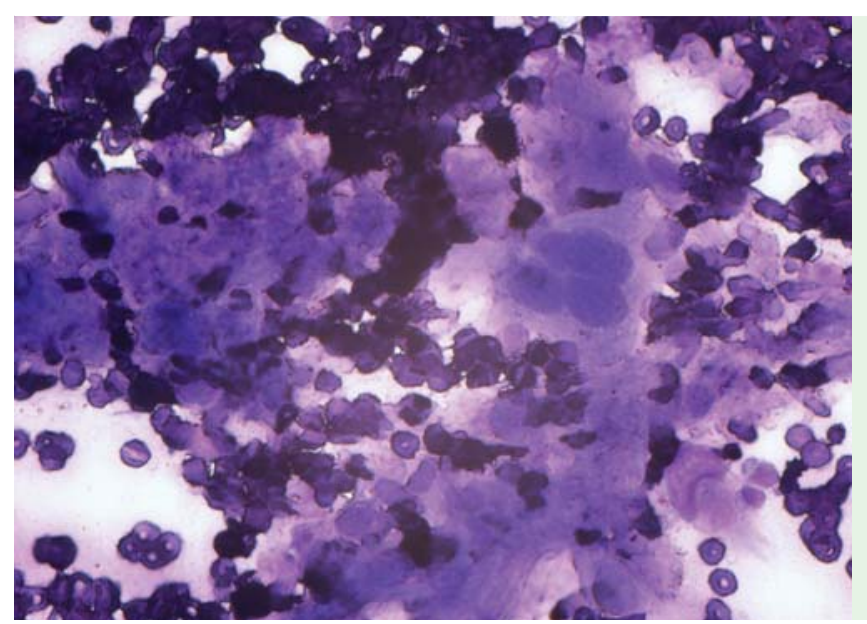

Fig. 4 Positive cytology smear showing clumps of atypical epithelial cells (MayGrünwald-Giemsa $\times 200$ ). 
EUS can accurately assess local tumor infiltration ( $\mathrm{T}$ stage) and detect regional or distant lymph nodes metastases ( $\mathrm{N}$ and M stage). Moreover, EUS-FNA significantly improves the specificity by enabling cytological diagnosis [1]. To the best of our knowledge this is the first reported case of peritonitis after EUS-FNA of a large metastatic celiac lymph node, although there are several reported cases of mediastinitis following EUS-FNA of mediastinal masses [2,3]. Antibiotic prophylaxis is not required for EUS-FNA of lymph nodes or solid lesions, being generally considered a safe, minimally invasive procedure with a low risk for bacteremia [4]. However, the presented case should make endosonographers more aware of the potential serious complications of EUSFNA.

Endoscopy_UCTN_Code_CPL_1AL_2AF

Competing interests: None
T. Cârțână ${ }^{1}$, A. Săftoiu ${ }^{1}$, C. Popescu ${ }^{2}$,

D. I. Gheonea ${ }^{1}$, T. Ciurea', I. Georgescu ${ }^{3}$

1 Research Centre of Gastroenterology and Hepatology, University of Medicine and Pharmacy, Craiova, Romania

2 Cytology Laboratory, Emergency Hospital, Craiova, Romania

3 General Surgery Department, Emergency Hospital, Craiova, Romania

\section{References}

1 Puli SR, Reddy JBK, Bechtold ML et al. Staging accuracy of esophageal cancer by endoscopic ultrasound: a meta-analysis and systematic review. World J Gastroenterol 2008; 14: $1479-1490$

2 Pai KR, Page RD. Mediastinitis after EUSguided FNA biopsy of a posterior mediastinal metastatic teratoma. Gastrointest Endosc 2005; 62: 980-981

3 Aerts JG, Kloover J, Los J et al. EUS-FNA of enlarged necrotic lymph nodes may cause infectious mediastinitis. J Thorac Oncol 2008; 3: 1191 - 1193

4 Adler DG, Jacobson BC, Davilla RE et al. ASGE guideline: complications of EUS. Gastrointest Endosc 2005; 61: 8-12
Bibliography

DOI $10.1055 / \mathrm{s}-0030-1256158$

Endoscopy 2011; 43: E122-E123

(c) Georg Thieme Verlag KG Stuttgart · New York . ISSN 0013-726X

Corresponding author

\section{T. Cârțână, MD}

Research Centre of Gastroenterology and Hepatology

University of Medicine and Pharmacy Craiova

1 Mai 66

200639 Craiova

Romania

Fax: +40-251-310287

tatiana_0313@yahoo.com 